\title{
Um Exemplo do Uso do Cinema como Ferramenta de Observação Teórica em Hospitalidade: Lilo \& Stitch (Walt Disney) ${ }^{1}$
}

\author{
Sergio dos Santos Clemente Júnior ${ }^{2}$ \\ Escola de Comunicações e Artes da Universidade de São Paulo \\ * Autor para correspondência: sergio_clemente@ig.com.br
}

\section{RESUMO}

O relato apresenta os resultados obtidos pelo uso do cinema em sala de aula, cujo objetivo foi observar a teoria sobre os domínios da Hospitalidade (CAMARGO, 2004), que defende o estudo do tema por dezesseis ângulos diferentes: os tempos de recepcionar, hospedar, alimentar e entreter, e os espaços doméstico, público, comercial e virtual. Para a observação e a discussão dessa base teórica, o pesquisador apresentou o desenho Lilo \& Stitch - obra cinematográfica dos estúdios Disney - a alunos do curso de graduação em Turismo da ECA-USP. A proposta foi que os alunos assistissem ao desenho na íntegra e então preenchessem o quadro proposto no estudo, identificando referências visuais no filme que pudessem explicar cada uma das interações tempo e espaço da Hospitalidade. O cinema, como ferramenta de observação empírica, tornou-se um facilitador da discussão, já que possibilitou à turma preencher os dezesseis quadrantes e permitiu explicar a teoria na prática com maior clareza de entendimento.

Palavras-Chave: Metodologia de Ensino; Recurso/Ferramenta de aula; Cinema em Sala de Aula; Observação Teórica em Hospitalidade; Lilo \& Stitch (Walt Disney).

\begin{abstract}
The purpose of this article is to present the results obtained from the use of cinema in the classroom whose objective was to observe the theory of the fields of Hospitality (CAMARGO, 2004), which advocates the subject of study by sixteen different quadrants: the times of reception, hosting, feed and entertain, and the domestic, public, commercial and virtual spaces. For observation and discussion of this theoretical basis the researcher presented the Lilo \& Stitch - cinematographic film of Disney Studios - to students of Tourism ECA-USP. It was proposed to the students to watch the whole film and to fill the indicated form. This proposal aimed to identify visual references in the film that could explain each one of the interaction time and spaces of Hospitality. The film as an empirical observation tool, has become a facilitator of the discussion, since the class allowed to fill the sixteen quadrants, allowing explain the theory into practice with greater clarity of understanding.
\end{abstract}

Keywords: Teaching Methodology; Teaching Tools; Cinema in the Classroom; Theoretical Observation in Hospitality ; Lilo \& Stitch (Walt Disney).

\section{Introdução}

A proposta deste relato é apresentar os resultados obtidos com o uso do cinema em sala de aula, cujo objetivo foi observar a teoria sobre os domínios da Hospitalidade estudada por Camargo (2004), que defende o estudo do tema por dezesseis ângulos diferentes, sejam eles: os tempos de recepcionar, hospedar, alimentar e entreter, e os espaços doméstico, público, comercial e virtual.

Para a observação e a discussão dessa base teórica, o pesquisador apresentou o desenho Lilo b
Stitch - obra cinematográfica dos estúdios Disney - aos alunos do curso de Graduação em Turismo da ECA-USP, na disciplina de Hospitalidade, de responsabilidade da Prof ${ }^{a}$. Dr ${ }^{a}$. Célia Maria de Moraes Dias.

A proposta era que, após assistirem ao desenho na íntegra, os alunos deveriam preencher o quadro proposto no estudo, identificando referências visuais no filme que pudessem explicar cada uma das interações tempo e espaço da Hospitalidade.

O cinema, usado como ferramenta de 
observação empírica, tornou-se um facilitador da discussão, uma vez que possibilitou à turma preencher os dezesseis quadrantes, o que permitiu explicar a teoria na prática com maior clareza de entendimento.

\section{Revisão da Literatura}

O tema central dos "domínios da hospitalidade" é o estudo das práticas sociais inseridas nos processos que envolvem a hospitalidade e que podem ser observadas e analisadas por dois ângulos distintos. $\mathrm{O}$ primeiro deles diz respeito aos "tempos sociais da hospitalidade humana" - o receber, o hospedar, o alimentar e o entreter pessoas. O segundo diz respeito aos "espaços sociais" nos quais o processo se desenrola: o doméstico, o público, o comercial e o virtual (CAMARGO, 2004; LASHLEY 2004). Camargo (2004, p. 52) sugere, para o estudo desses processos de hospitalidade, dois eixos nos quais são apoiadas as práticas sociais. $\mathrm{O}$ primeiro deles fala dos tempos sociais de receber, hospedar, alimentar e entreter pessoas, e o segundo fala dos espaços sociais nos quais os contatos de hospitalidade se desenrolam, quais sejam, o doméstico, o público, o comercial e o virtual.

Essa teoria elaborada por Camargo possibilita ao pesquisador analisar o tema hospitalidade por dezesseis ângulos diferentes, provenientes do cruzamento dos quatro "domínios" entre si, como mostra o quadro 1:

De acordo com a leitura de Camargo (2004), cada cruzamento propõe o estudo da Hospitalidade como descrito a seguir:

$\checkmark$ O Receber Doméstico - Compreendendo todos os pequenos gestos do cotidiano, o receber doméstico deve observar os esforços na recepção de quem chega à nossa casa. $\mathrm{O}$ autor julga que aqui encontramos a essência e a totalidade do campo da hospitalidade.

$\checkmark$ O Receber Público - A garantia do direito de ir e vir passa justamente pelo receber público. O espaço devidamente planejado de uma cidade tornará possível a sua interpretação pelo olhar de seus moradores e também de quem a visita. $\mathrm{O}$ autor ressalta que os costumes e tradições locais (dando especial atenção ao acento linguístico local) são elementos importantes na dimensão da hospitalidade pública.

$\checkmark$ O Receber Comercial - A discussão aqui é grande. $\mathrm{O}$ autor ressalta que nesse momento nos deparamos com a diferenciação daquele que recebe por prazer e aquele que recebe um pagamento pela

\begin{tabular}{|c|c|c|c|c|}
\hline & Recepcionar & Hospedar & Alimentar & Entreter \\
\hline Doméstica & $\begin{array}{l}\text { Receber pessoas } \\
\text { em casa, de forma } \\
\text { intencional ou } \\
\text { casual. }\end{array}$ & $\begin{array}{l}\text { Fornecer pouso } \\
\text { e abrigo em casa } \\
\text { para pessoas. }\end{array}$ & $\begin{array}{l}\text { Receber em casa } \\
\text { para refeições e } \\
\text { banquetes. }\end{array}$ & $\begin{array}{l}\text { Receber para } \\
\text { recepções e festas. }\end{array}$ \\
\hline Pública & $\begin{array}{c}\text { Recepção em } \\
\text { espaços e órgãos } \\
\text { públicos de livre } \\
\text { acesso. }\end{array}$ & $\begin{array}{c}\text { Hospedagem } \\
\text { proporcionada } \\
\text { pela cidade e pelo } \\
\text { país. }\end{array}$ & $\begin{array}{l}\text { A gastronomia } \\
\text { local. }\end{array}$ & $\begin{array}{l}\text { Espaços públicos } \\
\text { de lazer e eventos. }\end{array}$ \\
\hline Comercial & $\begin{array}{l}\text { Os serviços } \\
\text { profissionais de } \\
\text { recepção. }\end{array}$ & Hotéis. & A restauração. & $\begin{array}{c}\text { Eventos e } \\
\text { espetáculos. } \\
\text { Espaços privados } \\
\text { de lazer. }\end{array}$ \\
\hline Virtual & $\begin{array}{l}\text { Folhetos, cartazes, } \\
\text { fôlderes, internet, } \\
\text { telefone, e-mail. }\end{array}$ & $\begin{array}{l}\text { Sites e hospedeiros } \\
\text { de sites. }\end{array}$ & $\begin{array}{l}\text { Programas na } \\
\text { mídia e sites de } \\
\text { gastronomia }\end{array}$ & $\begin{array}{l}\text { Jogos e entreteni- } \\
\text { mento na mídia. }\end{array}$ \\
\hline
\end{tabular}

Quadro 1 - Os Domínios da Hospitalidade. Fonte: CAMARGO, 2004, p. 84. 
prestação de hospitalidade. Aqui se estudam todos os equipamentos e acomodação comercial, hotéis, pousadas, hospitais, entre outros.

$\checkmark$ O Receber Virtual - Camargo sinaliza aqui uma nova forma de estudar a hospitalidade. Aquela que se faz virtualmente, seja por elementos efetivamente virtuais (por exemplo, o telefone e o e-mail), assim como os midiáticos (folhetos, cartazes, fôlderes), e nas palavras do próprio autor: "cada vez mais onipresente a internet e seus sites" (2004, p. 58).

$\checkmark$ O Hospedar Doméstico - Acomodar alguém na nossa casa é uma abertura para, na grande maioria das vezes, mundos totalmente diferentes, cujos hábitos mais corriqueiros poderão gerar desconforto para quem recebe e para quem é recebido. Camargo sinaliza a amplitude desse estudo, que inclusive pressupõe que o hospedado está sob a guarda e sob a segurança do hospedeiro.

$\checkmark$ O Hospedar Público - $\mathrm{O}$ autor sinaliza que o hospedar público antes de qualquer coisa é um hospedar político. A cidade hospeda de maneira adequada no momento em que se torna legível e interpretável aos olhos de seus visitantes, e essa situação afeta diretamente não só os destinos turísticos, mas qualquer centro urbano ou rural no qual se receba uma pessoa vinda de fora.

$\checkmark$ O Hospedar Comercial - Aqui se estudam efetivamente a formatação e a dinâmica dos equipamentos comerciais de hospedagem.

$\checkmark$ O Hospedar Virtual - O autor não ampliou de forma significativa o hospedar virtual, deixando como questionamento se o espaço vitual é privado ou público. Sinaliza, entretanto, que o estudo do hospedar virtual deve passar pelos "locais" nos quais a informação fica armazenada para consulta de seu público, por exemplo a hospedagem de sites na internet.

$\checkmark$ O Alimentar Doméstico - Uma das formas mais hospitaleiras de receber o outro é oferecendo-lhe comida. Essa ação muda a rotina da família que recebe, não somente pelo aumento da quantidade de alimento oferecido, mas também quanto aos cuidados de higiene e limpeza. Talvez a mais importante troca de experiência nesse alimentar seja a culinária local, que proporciona ao visitante experiências, por vezes, novas e/ou exóticas.

$\checkmark$ O Alimentar Público - A culinária local é extremamente representativa na hospitalidade pública; porém, o autor indica que esse estudo deve fugir da observação pura e simples da gastronomia local, abrangendo o acesso aos itens que compõem essa culinária, bem como a observação dos hábitos alimentares da população, que no conjunto acabam representando muito mais o alimentar público da cidade em questão.

$\checkmark$ O Alimentar Comercial - O alimentar comercial se foca nos esforços de atendimento de restauração - os equipamentos comerciais de alimentação -, que são os restaurantes, as lanchonetes, os bares, entre outros.

$\checkmark$ O Alimentar Virtual - Aqui também não há uma profundidade de estudo por parte do autor, mas este indica que se devem observar a oferta de informações virtuais sobre a gastronomia e a oferta da culinária local por meio dos equipamentos virtuais de comunicação para o visitante.

$\checkmark$ O Entreter Doméstico - O autor sinaliza aqui que o estudo do entreter doméstico recai, sobretudo, na arte da comunicação interpessoal que se processa na conversa, além de todos os rituais e os esforços para entreter quem está hospedado na nossa casa.

$\checkmark$ O Entreter Público - Esse estudo se centra em todos os equipamentos de lazer e entretenimento públicos disponíveis na cidade.

$\checkmark$ O Entreter Comercial - Da mesma forma, esse estudo se detém em todos os equipamentos de lazer e entretenimento agora privados disponíveis na cidade.

$\checkmark$ O Entreter Virtual - A TV, o rádio e a internet são abordados nesse estudo, que em conjunto com os dois anteriores proporcionam entretenimento ao visitante.

\section{Métodos e Técnicas}

Para a observação e a discussão dessa base teórica, o pesquisador apresentou o desenho Lilo \& Stitch aos alunos de duas turmas do curso de Turismo da ECA-USP, em disciplina de Hospitalidade 
ministrada pela Prof ${ }^{a}$. Dra ${ }^{\text {a }}$ Célia Maria de Moraes Dias em 2012 e 2013. A proposta foi a de que, após assistirem ao desenho na íntegra, os alunos preenchessem o quadro proposto no estudo, identificando referências visuais no filme que pudessem explicar cada uma das interações tempo e espaço da Hospitalidade.

\section{O Objeto de Estudo: Lilo \& Stitch - Sinopse} do Desenho: Lilo (Daveigh Chase) é uma garota havaiana de cinco anos, órfã e que vive com sua irmã adolescente Nani (Tia Carrere). Ela tem por hábito cuidar de animais menos favorecidos e costuma coletar lixo reciclável nas praias havaianas para comprar comida para os peixes. Todos os dias pela manhã ela nada até o alto-mar para alimentá -los com pão e pasta de amendoim. Enquanto isso, em um planeta distante, autoridades alienígenas conseguem capturar um perigoso ser geneticamente modificado, cuja força e inteligência estão acima do normal e que não apresenta nenhuma tendência à bondade. Quando os policiais intergalácticos vão enviá-lo para um planeta-prisão, o monstrinho consegue fugir e, acidentalmente, cai na Terra, mais precisamente no Havaí. Após ter sido atropelado por um caminhão e confundido com um cachorro, vai parar em um abrigo de adoção para animais abandonados. Para escapar da polícia intergaláctica que ainda o persegue, Stitch (Chris Sanders) esconde quatro de suas seis pernas e decide se passar por um cachorro comum. É aí então que eles se encontram, quando Lilo e sua irmã estão buscando um cachorrinho para adoção. Lilo, ao deparar com o animal que "fala", se encanta rapidamente e decide adotá-lo. Acreditando que o novo amigo é realmente um bichinho domesticável, a menina começa a chamá-lo de Stitch. O problema é que o extraterrestre tem uma séria propensão a destruir tudo o que vê pela frente, mas, com o tempo, se desenvolve um grande e bonito laço de amizade entre os dois. Lilo \& Stitch é um clássico dos Estúdios Disney do ano 2002 e resgata em sua trilha sonora a inesquecível e lendária música de Elvis Presley. Assista ao desenho e divirta-se com as peripécias dessa dupla hilariante em cenários exuberantes (mesmo que em desenho) que retratam as maravilhosas ilhas havaianas. Essa aventura Disney está repleta de comédia, emoção e reflexão e é diversão garantida para toda a família. Ohana!!!

\section{A Técnica Utilizada}

Os alunos foram orientados em sala de aula quanto à ténica a ser utilizada para uso do cinema como metodologia de ensino e receberam, cada um, uma folha que continha o quadro dos Domínios da Hospitalidade, em branco. Foi feita a leitura do Quadro completo proposto por Camargo (2004) e uma breve explicação dos conceitos centrais esperados pelo autor em cada cruzamento dos domínios (importante ressaltar que a leitura da teoria já tinha sido proposta à turma nas semanas anteriores à aplicação da atividade). Durante a exibição do desenho, cada aluno deveria preencher individualmente, e segundo a sua interpretação (note-se que não houve durante a exibição a interferência do professor), cenas que representassem os cruzamentos do quadro. Após assistir ao desenho, os alunos se reuniram em grupos de quatro a seis integrantes e começaram uma discussão para chegarem a um consenso sobre qual (quais) cena(s) iriam apresentar aos demais grupos como representativas de cada cruzamento. Para embasar essa discussão, cada grupo recebeu uma cópia do Quadro completo como é apresentado na obra de Camargo (2004, p. 84). Feito isso, abriu-se a discussão a toda a sala, e cada grupo deveria defender a cena que escolheu conforme a teoria em estudo, fechando-se apenas um quadro que contivesse a(s) cena(s) - a melhor, segundo os alunos - representando cada cruzamento dos Domínios da Hospitalidade.

\section{Resultados e Discussão}

Depois de assistirmos ao desenho Lilo \& Stitch na íntegra, os alunos reunidos em grupos tiveram como atividade o preenchimento do quadro proposto por Camargo (2004, p. 84) com referências visuais que pudessem explicar cada cruzamento dos domínios da hospitalidade. Segue o resultado final após a compilação e consenso dos grupos: 
$\checkmark$ O Receber Doméstico - A recepção de Stitch na casa de Lilo, após ter sido adotado, mesmo que como um cachorro. Esse acolhimento aconteceu principalmente na sala de estar, na cozinha e no quarto de Lilo.

V O Receber Público - A "recepção" de Stitch na Terra. Após sua nave espacial cair na Terra, o alienígena, ao tentar atirar em um sapo que o observava na estrada, foi atropelado por um caminhão. Embora tenha sido socorrido pelo motorista, essa foi a primeira recepção que teve no local. Outra cena interessante, citada pelos alunos, é a de quando a Juíza do planeta de Stitch dá o seu veredicto de que o alienígena pode ficar na Terra, assim que Lilo leu um trecho descrito no certificado de compra do "cachorro": este indicava que, a partir daquela data, o animal era de propriedade dela; segundo as leis dos Estados Unidos, a posse do animal seria de Lilo, permitindo assim que ele permanecesse na Terra junto da família que o adotou quando de sua chegada. Ao final dessa mesma cena, a Terra "acolhe", além de Stitch, os dois alienígenas que foram mandados ao nosso planeta para capturar a criatura.

$\checkmark$ O Receber Comercial - As cenas indicadas foram a da recepção de Stitch no canil de adoção de animais (onde foi recebido como um cachorro comum, apesar de estranho) e as cenas nas quais aparecem as recepções do hotel e do restaurante onde Nani buscava emprego.

$\checkmark$ O Receber Virtual - Do planeta do qual Stitch é oriundo, os personagens viam a Terra por "informações" intergalácticas, usando um transmissor de imagem como um pequeno televisor. Nessas imagens apareceram informações do Havaí, local onde a nave de Stitch caiu.

$\checkmark$ O Hospedar Doméstico - Acontece, sobretudo, quando Lilo prepara uma caminha para Stitch em seu quarto, ao mesmo tempo que este passa a destruir tudo o que vê pela frente. Um símbolo indicado pelos alunos como hospedar doméstico foi a rede, na qual Nani e Lilo se encontram em uma das cenas mais emocionantes do desenho, cena esta na qual a irmã mais velha explica o quão importante é Lilo para ela e ressalta a grande frase do filme:
"Ohana!! A mais forte representação da fé havaina".

$\checkmark$ O Hospedar Público - Aqui os alunos indicaram as cenas que se passam durante a busca de Nani por um trabalho. Essas são cenas que mostram a dinâmica da cidade e como, pelas imagens, o turista teria, sim, condição de reconhecer o espaço sentindo-se parte dele.

$\checkmark$ O Hospedar Comercial - Há cenas que se passam nas dependências de um hotel, estabelecimento tipicamente comercial de hospitalidade.

$\checkmark$ O Hospedar Virtual - Esse quesito foi de difícil consenso dos alunos, mas se fechou um entendimento de que as informações contidas no transmissor intergaláctico do planeta alienígena hospedavam virtualmente as informações da Terra. O que, segundo a teoria de Camargo, está correto.

$\checkmark$ O Alimentar Doméstico - A cena indicada de forma unânime pelos alunos foi Stitch assaltando a geladeira da casa de Lilo no meio da noite, quando é surpreendido por Nani, que se assusta ao ver a real forma do animal.

$\checkmark$ O Alimentar Público - A indicação foi a da cena na praia, que mostra equipamentos informais de alimentação pública (carrinho de pipoca, sorvete e cachorro-quente). Inclusive com destaque para a bola de sorvete de um turista que cai por duas vezes durante o desenho, em cenas diferentes.

$\checkmark$ O Alimentar Comercial - Assim como no hospedar comercial, há cenas que se passam nas dependências de um restaurante, estabelecimento tipicamente comercial de restauração.

$\checkmark$ O Alimentar Virtual - Aqui, houve uma controvérsia, mas que deu sentido à teoria. A cena indicada foi aquela em que um dos policiais (o de um olho só) é devorado por pernilongos, estando no meio da mata próximo à casa de Lilo. Essa cena mostra, em alguns segundos antes de ele ficar totalmente coberto pelos pernilongos, que, segundo seu registro virtual - uma espécie de transmissor intergaláctico -, "ele conhecia o hábito alimentar da Terra", colocando de maneira hilária o pernilongo no topo da cadeia.

$\checkmark$ O Entreter Doméstico - Uma cena destacada foi a da leitura do conto "O Patinho Feio", que a personagem Lilo lê para o seu novo amiguinho, 
o estranho cachorro que acabara de adotar. Uma das cenas mais hilariantes do desenho, apresentada pelos alunos como entreter doméstico, é quando Lilo ouve o disco de vinil de Elvis Presley usando Stitch como um gramofone. E, por fim, as cenas de comemoração de datas festivas como o Natal, a Páscoa, o Halloween e a festa de aniversário, que aparecem retratadas em fotos ao final do desenho, quando Stitch e seus companheiros alienígenas já estão totalmente integrados à vida em família na Terra.

$\checkmark$ O Entreter Público - As cenas indicadas foram as que se passam na praia, enquanto os banhistas tomam banho de mar, tomam banho de sol e brincam na água (sobretudo nas atividades de natação e surf).

$\checkmark$ O Entreter Comercial - Foram apontadas duas cenas referentes ao entreter comercial. A primeira traz a dança típica com fogo feita por David (namorado de Nani) aos turistas do restaurante. Nessa cena inclusive ele coloca fogo no telhado de palha do quiosque onde se apresentava. A segunda cena indicada pelos alunos foi o ensaio da dança típica havaiana (o ula ula), do qual Lilo fazia parte, e no fim do desenho Stitch também entra na dança, literalmente.

$\checkmark$ O Entreter Virtual - Pelo mesmo transmissor intergaláctico, os personagens alienígenas viam cenas da Terra e em todas elas havia pessoas de alguma forma se divertindo, fosse em família, fosse na praia. As imagens serviram aos personagens para definir um padrão do "Terráqueo".

Vale apenas ressaltar aqui que as cenas indicadas acima são as melhores na visão dos alunos, não houve a interferência do professor quanto às suas escolhas; porém, todas, sem exceção, representam a teoria estudada de maneira adequada.

\section{Considerações Finais}

O professor deve conduzir seus alunos em busca de uma análise e de uma discussão mais aprofundada acerca dos itens teóricos correspondentes a cada nível ou estágio da sua formação. Dessa forma, sabemos que a escolha da metodologia de ensino, bem como da forma como se dará a avaliação dos alunos, é de competência do docente.
A opção metodológica do pesquisador quanto ao uso do cinema em sala de aula foi a de não estudar um dado recorte do desenho, mas este em sua totalidade, observando-o como filme de exploração. Buscou-se então, nessa experiência, trazer os alunos para uma reflexão mais informal, mesmo que totalmente baseada, apoiada e conduzida na proposta desenhada pela teoria em questão.

Para que a aula se tornasse mais produtiva e interessante, o pesquisador adotou a utilização de produções cinematográficas para que, a partir delas, fossem explicadas teorias importantes na formação de alunos de graduação.

Nessa oportunidade, a utilização do desenho Lilo \& Stitch, cujo método buscou a observação e a interpretação da teoria sobre os Domínios de Hospitalidade, proporcionou à turma uma discussão calorosa e extremamente rica na busca do entendimento teórico para que se pudesse fazer o correto preenchimento do quadro proposto no estudo.

A técnica utilizada pelo professor procurou inverter a ordem natural de uma aula convencional, na qual o docente explica a teoria e tenta ao final da aula, por meio de questionamentos aos alunos, identificar se a turma entendeu o que foi exposto.

A proposta, que consistiu em solicitar anteriormente a leitura da teoria, no dia da atividade fazer uma breve revisão desta, previamente estudada, assistir ao filme na íntegra e procurar, de maneira prática e lúdica, relacionar o conteúdo teórico ao desenho a que assistiram, trouxe como responsabilidade ao aluno a ilustração e a explicação teórica.

Percebeu-se, dessa forma, que entender e ilustrar a teoria tornou-se muito mais fácil. $\mathrm{O}$ cinema abriu caminhos para uma discussão teórica menos dificultosa, mais simples, e que tirou dos próprios alunos as respostas aos seus questionamentos.

A mesma metodologia tem sido utilizada pelo professor-pesquisador com outros filmes, também apresentados na íntegra, como, por exemplo: o filme Click para explicar "Conflitos", o filme Vem Dançar para explicar "Concorrência", o filme Avatar para explicar "Dado, Informação e Conhecimento", o desenho Pinóquio para estudar "Los Falsos Amigos" no ensino do Espanhol, e os filmes Branca 
de Neve e os Sete Anões e Espelho, Espelho Meu para discutir a "Análise de Discursos". Todas essas experiências estão sendo reunidas em um livro com previsão de ser publicado em 2018.

\section{Notas}

1 Trabalho apresentado no formato poster, no I Congresso de Graduação da USP, no Centro de Convenções Rebouças, em São Paulo-SP, de 25 a 27 de maio de 2015.

2 Mestre em Ciências da Comunicação - ECA / USP. Mestre em Hospitalidade - Universidade Anhembi Morumbi (UAM) - SP. Pós-Graduado em Administração Hoteleira (Senac) - SP. PósGraduado em Comunicação de Marketing (UAM) - SP. Graduação em Comunicação Social com
Habilitação em Publicidade e Propaganda (UAM) - SP. Professor Tutor em EaD no Senac São PauloSP, e-mail: sergio_clemente@ig.com.br

\section{Referências Bibliográficas}

CAMARGO, Luiz Octávio de Lima. Hospitalidade. São Paulo: Editora Aleph, 2004.

LASHLEY, Conrad. "Para um Entendimento Teórico". In: LASHLEY, Conrad \& MORRISON, Alison (orgs.). Em Busca da Hospitalidade. Perspectivas para um Mundo Globalizado. Barueri: Editora Manole, 2004.

LILO \& STITCH. Direção de Dan De Blois e Chris Sanders. Buena Vista Pictures Distribuidora, 2002. Site oficial disponível em: 〈http://www.disney.com/stitch〉. Acessado em 14 fev. 2015. 